\title{
The Metabolic Response to Hypocaloric Protein Diets in Obese Man
}

\author{
Errol B. Marliss, Frederick T. Murray, and Azima F. Nakhooda, Endocrine- \\ Metabolism Division, Toronto General Hospital, University of Toronto, \\ Toronto, Ontario
}

\begin{abstract}
A B S T RACT Exogenous protein in the absence of other calories can cause protein-sparing, but the mechanisms involved are controversial. It has been postulated that low insulin and high fat-derived substrate levels are necessary and sufficient conditions for such protein-sparing. We therefore established such conditions with differing protocols of protein input to define the role of protein input in mediating the response. Three groups of obese, nondiabetic subjects received the following diets: (1) $82.5 \pm 1.0 \mathrm{~g}$ protein/day (400 cal/day) for 21 days, $n=7$; (2) the same, but as a refeeding diet for 7 days after 21-28 days of total fasts, $n=7$; and (3) commencing with the same input, but with daily stepwise decrements over 14 days to 19.4 $\pm 2.2 \mathrm{~g} /$ day, then maintained an additional 7 days, $n=4$. Diet 3 gave approximately the amount and pattern of protein lost during total fasting.

The circulating hormone and substrate responses of diets 1 and 3 were comparable and resembled those of total fasts, in that plasma glucose and insulin fell and free fatty acids rose. Blood levels of alanine, pyruvate, and other glucogenic amino acids fell and blood levels of branched-chain amino acids rose transiently. Blood 3-hydroxybutyrate levels and urinary excretion were greater in diet 3 than diet 1 , but less than in total fasting. Nitrogen balance in diet 1 was transiently negative, but in equilibrium from 12 to 21 days. In diet 3 , it was constantly negative at $-6 \mathrm{~g} / \mathrm{day}$, the values also observed at 21 days of fasting. Mean 3-methylhistidine excretion decreased by $170 \mu \mathrm{mol} /$ day in diet 1 and 107 $\mu \mathrm{mol} /$ day in diet 3 , reflecting decreased muscle protein catabolism. The refed, protein-depleted subjects, diet 2, showed an increase in plasma glucose without alteration in insulin levels. Free fatty acid and ketone
\end{abstract}

This work was presented in part at the Annual Meetings of the Canadian Society for Clinical Investigation, 26 January 1977 (1), and at the American Society of Clinical Nutrition, 29 April 1977 (2).

Received for publication 29 June 1977 and in revised form 16 March 1978. body levels decreased to those of the steady state observed in diet 1. Glucogenic and branched-chain amino acids decreased transiently. Nitrogen balance became positive, and the low 3-methylhistidine excretion increased by $152 \mu \mathrm{mol} / \mathrm{day}$.

The differing responses of nitrogen balance could not be accounted for on the basis of levels of insulin or of fat-derived substrates. The primary determinants of the protein-sparing observed appeared to be the protein supply itself, and the magnitude of the decrease in endogenous protein catabolism. The positive balance on refeeding after prior depletion of protein stores was likely due to the exogenous supply, combined with decreased catabolism and considerably increased reutilization.

\section{INTRODUCTION}

"Protein-sparing", defined as any decrement in body protein loss from that occurring in the absence of exogenous nutrients, may be achieved in a variety of ways. Energy (measured in calories) alone, without protein, can curtail such loss. The classical example is the sparing of protein by exogenous glucose (3). However, it is axiomatic that exogenous protein is required for maintenance of equilibrium and for accretion of body protein. Thus, by definition, exogenous protein alone can be protein-sparing. Though this principle has been recognized for many decades, it has recently received increased application in nutritional therapies, notably in intravenous feeding and in weight-reducing diets for obesity.

The mechanisms whereby exogenous protein, in hypocaloric amounts, spares protein are as yet incompletely understood. Factors recognized to be involved have been reviewed recently (4). It has been postulated that the prime mediator is the lower insulin level which prevails when protein is given in the absence of carbohydrate $(5,6)$. The inhibition of adipose tissue lipolysis has been generally accepted to be the most potent effect of basal or elevated levels of insulin. 
Therefore, it was suggested that such lowered levels allow for a greater part of the caloric deficit to be provided from endogenous fat. Thus it follows that the greater the rate of fat mobilization, the fewer the calories which must be produced from protein catabolism, resulting in protein-sparing. Implicit in this hypothesis is that any elevation of insulin levels would impede this process, resulting in less effective protein-sparing $(6,7)$. We have recently presented evidence that this is not the case: protein plus hypocaloric amounts of glucose intravenously (in the postoperative patient) result in elevated insulin, lowered free fatty acid, and ketone body levels, but no decrease in protein-sparing when compared to protein alone (8). Further, protein plus hypocaloric amounts of lipid result in low insulin and elevated fat-derived substrates, but again with the same protein-sparing. This led us to hypothesize $(a)$ that the principal determinant of protein-sparing is the protein supply itself and, (b) that caloric deficits are provided primarily from endogenous fat irrespective of insulin or fatderived substrate levels. The latter function could be described as a "caloristat", set at the requisite energy demand, and able to quantify exogenous supply and respond by mobilizing fat to precisely fill the deficit. The operation of both the sensor and effector limbs of such a caloristat require further definition.

We have previously studied nutritional states in which provision of protein with added calorie input has modified both insulin and energy substrate levels $(8,9)$. The present study was designed to examine the hypothesis that protein supply itself determines the resultant protein-sparing, by fixing insulin at comparably low levels during different inputs of hypocaloric amounts of protein. Levels of hormone and energy substrates, nitrogen balance, and excretion of 3-methylhistidine were monitored to allow for inferences as to the mechanisms of the responses observed. The importance of understanding mechanisms operative in such states is underscored by the current widespread use of so-called "protein-sparing modified fast" for weight reduction in obesity $(10-14)$ and in "protein-sparing therapies" employing intravenous amino acids alone in postoperative $(8,15)$ as well as prolonged intravenous nutrition (16). ${ }^{1}$ For the same reason, parameters reflecting electrolyte, acid-base, and other clinical variables have been monitored to assess the safety of such therapies.

\section{METHODS}

Subjects and procedures. 14 obese subjects from 19 to 52 yr of age, 10 female and 4 male, were admitted to the

\footnotetext{
${ }^{1}$ Greenberg, G. R., E. B. Marliss, G. H. Anderson, and K. N. Jeejeebhoy. Protein-sparing therapy in patients with gastrointestinal disease. Effect of infusing different levels of amino acids. Submitted for publication.
}

Clinical Investigation Unit of the Toronto General Hospital. One female was studied on three occasions, and another female and one male were studied twice. Each had been informed of the nature, purpose, and possible risks involved in the diets and blood sampling, and consent was obtained as prescribed by a University of Toronto human experimentation committee which had approved the protocol. Some of the subjects of the constant, refed, or total fasting diets underwent other procedures before or subsequent to those of the present report, which were sufficiently remote in time to have no effect upon the variables reported. The latter studies are published elsewhere (17-20). The patients were admitted during long-term out-patient follow-up for the management of obesity. However, they were directed not to practice caloric restriction for $1 \mathrm{wk}$ before admission.

All subjects had normal fasting and postprandial plasma glucose concentration and were free from clinical and laboratory evidence of hepatic, renal, and cardiovascular disease, and gout. A 3 to 7-day period in hospital on a weight-maintaining diet of at least 2,500 calories (40\% carbohydrate, $40 \%$ fat, and $20 \%$ protein) preceded the constant and decreasing protein diets and total fasts. A minimum of $1,500 \mathrm{ml}$ water was consumed daily, and one multivitamin tablet (Beminal, Ayerst Division of American Homes Products Corp., N. Y.) and $16 \mathrm{meq}$ of potassium as $\mathrm{KCl}$ (Slow-K, Ciba Pharmaceutical, Co., Division of Ciba-Geigy Corp., Summit, N. J.) were administered. Periodic single doses of mineral oil were given during protein diets, which otherwise uniformly produced severe constipation.

Continuous 24-h urine collections were made without preservative, kept at $4^{\circ} \mathrm{C}$, then frozen in several aliquots at $-20^{\circ} \mathrm{C}$. Blood was obtained from an antecubital vein with minimal stasis, at 7-9 a.m., in the overnight fasted state. Daily weight and fluid balance records were kept; fecal collections were not made. Blood pressure was monitored twice daily for postural changes. Weekly electrocardiograms, serum electrolytes, and renal and liver function variables were obtained to assure adequate monitoring.

Seven subjects consumed a constant protein intake for 21 days (diet 1), seven others were refed the same intake for 7 days after 21-28 days of total fasting (diet 2) and four subjects consumed a diet with daily stepwise decrements (of $0.5 \mathrm{~g}$ nitrogen) over the first 14 days followed by constant intake for a further 7 days (diet 3).

The diets were calculated according to individual tastes, employing varying proportions of egg white, beef tenderloin, sole, skim milk cottage cheese, water-packed canned tuna, shrimp, chicken, and was occasionally supplemented with casein hydrolysate (Casilan, Glaxo-Allenburys, Toronto, Ontario). For the constant and refed diets ( 1 and 2), total calories varied from a mean of 368-404 in individual subjects, with a mean of $393 \pm 7$ (SEM) for all 14 studies. Calculated protein intakes, according to standard tables (21), were $74.5 \pm 1.3 \mathrm{~g} /$ day; using the measured nitrogen contents of the components, these intakes were $82.5 \pm 1.0 \mathrm{~g} /$ day $(81 \%$ of calories). (All results are presented using the measured values for each component of the diet). Calculated fat intake was $6.9 \pm 0.1 \mathrm{~g} /$ day $(62 \pm 1 \mathrm{Kcal} / \mathrm{day})$, representing $16 \%$ of calories. Carbohydrate contributed $3.2 \pm 0.4 \mathrm{~g} /$ day $(12.8 \pm 1.6 \mathrm{Kcal} /$ day $)$, $3 \%$ of caloric input. For the decremental protein diet (diet 3), nitrogen input was as shown in the results, (Fig. 5), and fat and carbohydrate were maintained at the same proportions of the total caloric input. On days 14-21, caloric input was $92 \pm 10 \mathrm{Kcal} /$ day with $19.4 \pm 2.2 \mathrm{~g} /$ day as protein, 1.2 $\pm 0.5 \mathrm{~g} /$ day as fat, and $0.5 \pm 0.2 \mathrm{~g} /$ day as carbohydrate.

Biochemical methods. The venous blood samples were divided into several aliquots. One was immediately deproteinized in an equal volume of cold $10 \%(\mathrm{wt} / \mathrm{vol})$ perchloric 
acid, kept on ice until centrifuged at $4^{\circ} \mathrm{C}$, then the supernates were frozen at $-20^{\circ} \mathrm{C}$ in aliquots until assay. Heparinized blood was added to tubes containing aprotinin (Trasylol, 10,000 Kallikrein inhibitor units/ml, FBA Pharmaceuticals, New York), in a volume $1 / 10$ th that of the added blood. These samples were cooled, centrifuged at $4^{\circ} \mathrm{C}$, and aliquots of plasma stored at $-20^{\circ} \mathrm{C}$. Heparinized blood was kept anaerobically in a sealed syringe for estimation of $\mathrm{pH}$, $\mathrm{PCO}_{2}$, and calculation of total $\mathrm{CO}_{2}$. Further samples were added to oxalate-fluoride tubes for glucose (22) and ureanitrogen determination; to EDTA tubes for hemoglobin, hematocrit, cholesterol, and triglyceride determinations; and to tubes without anticoagulant for uric acid, creatinine, glutamic-oxaloacetic transaminase, lactic dehydrogenase, alkaline phosphatase, and electrolyte estimation by standard autoanalyzer techniques.

Urine was collected over 24 -h periods at $4^{\circ} \mathrm{C}$, well mixed, and aliquots were analyzed daily (for urea, creatinine, and uric acid), or frozen at $-20^{\circ} \mathrm{C}$ until assay for ammonium nitrogen or 3-methylhistidine. For the latter, an equal volume of urine and $10 \%$ perchloric acid was mixed and the samples centrifuged just before analysis.

Assay of most metabolic intermediates was by enzymic microfluorimetric methods modified from published techniques to enable assay of replicates on 5 or $10 \mu$ l of blood at the 1:2 dilution in the perchloric acid supernate. An Aminco Fluoromicrophotometer (American Instrument Co., Travenol Laboratories Inc., Silver Spring, Md.) was used. Lactate (23), pyruvate (24), 3-hydroxybutyrate (25), and acetoacetate (26), and glycerol (27) were determined in this fashion. Acidic, neutral, and basic amino acids were estimated in whole blood by a single-column method (28) employing a lithium buffer system with a Beckman 120C amino acid analyzer (Beckman Instruments, Inc., Spinico Div., Palo Alto, Calif.) equipped with an Autolab Computer (SpectroPhysics Inc., Autolab Div., Santa Clara, Calif.). Reduced glutathione elutes in a separate peak well resolved from those of other amino acids by this protocol, but that of the oxidized form coelutes with aspartate. For urine 3-methylhistidine, an elution protocol using a 6-cm column on a Beckman $121 \mathrm{M}$ amino acid analyzer (Beckman Instruments, Inc., Spinico Div.) was developed. This enabled assays to be performed in $45 \mathrm{~min}$, using a lithium citrate buffer, $\mathrm{pH} 4.17$ at $64^{\circ} \mathrm{C}$ (Beckman Instruments, Inc., Spinico Div.), with 98 $\pm 4 \%$ recovery of standard added to urine perchloric acid supernates.

Plasma with aprotinin was employed for the following assays. Free fatty acids were assayed in single Dole extracts by the radiochemical microtechnique of $\mathrm{Ho}(29)$, in which no interference by organic anions occurs. Immunoreactive insulin $(\text { IRI })^{2}$ was estimated using a radioimmunoassay system employing a coated-charcoal separation of free from bound hormone (30), highly purified human insulin standard, monoiodinated ( $\left.{ }^{125} \mathrm{I}\right)$-pork insulin tracer (both from Novo Research Laboratories, Copenhagen, Denmark), and antiserum kindly provided by Dr. Peter H. Wright, (Indianapolis, Ind.). Immunoreactive glucagon (IRG) was assayed using the same separation technique, purified porcine glucagon standard, monoiodinated (125I) pork glucagon label (Novo Research Laboratories), and antiserum 30K from Dr. R. H. Unger (Dallas, Tex.). A blank without antibody was run with each sample for "nonspecific binding". The antiserum used is relatively specific for "pancreatic glucagon" as distinct from enteroglucagon, but is recognized to cross-react with a high molecular weight component, probable glucagon precursors

${ }^{2}$ Abbreviations used in this paper: IRG, immunoreactive glucagon; IRI, immunoreactive insulin.
(31), and probably fragments of the native hormone. All assays performed on aprotinin-containing plasma were corrected for the plasma dilution introduced, by use of the concurrently obtained hematocrit determinations.

Urine nitrogen components were assessed as follows: Urea nitrogen was obtained by the autoanalyzer method (32), ammonium nitrogen using a specific ion electrode (Orion Research Inc., Cambridge, Mass.), and creatinine and uric acid by autoanalyzer methods $(33,34)$. The difference between the total of measured components and total nitrogen, a relatively constant $0.5 \mathrm{~g} / \mathrm{d}$ during fasting (35), was added to the total. This value was verified for several samples in each diet by measurement of total nitrogen by a micro-Kjeldahl technique (36). Integumentary nitrogen loss was presumed to be constant during the diets employed, and calculated as $5 \mathrm{mg} / \mathrm{kg}$ per day and included estimates of protein loss (37). Finally, a value of $0.4 \mathrm{~g} /$ day of fecal loss was added to the values for nitrogen loss, based upon reference 14 , which employed similar hypocaloric protein diets. This is likely to be an overestimate (especially in the decreasing protein diet) because the patients on both diets experienced small bowel movements, and only once every 4-6 days. Three different aliquots of each of the large, uniform stocks of individual protein sources used throughout were assayed for total nitrogen in water homogenates. These values were employed in calculating intake in every patient for each day as described above.

All determinations, except amino acids, were performed in duplicate or triplicate. Statistical analyses were performed using the Student's paired $t$ test to test for the time-related effects of each diet, and the unpaired $t$ test to test for intergroup comparisons.

\section{RESULTS}

The clinical response to the three regimens was similar. With diets 1 and 3, initial rapid weight loss occurred over 7-10 days (attributable largely to fluid volume contraction), followed by a constant loss $\cong 300$ g daily. The total loss was comparable in diets 1 and 3 . A gain of $0.9 \pm 0.6 \mathrm{~kg}$ occurred with refeeding (Table I). All subjects had a demonstrable postural change in blood pressure, and in one-third this was symptomatic. None showed significant changes in liver-function studies or electrocardiograms, and serum sodium and chloride were maintained normal, though serum potassium was usually at the lower limit of the normal range. The mild, compensated metabolic acidosis was not different in fasting or diets 1 and 3, but was neutralized during refeeding (Table II). Hunger remained suppressed in association with the presence of acidosis. Serum uric acid showed an initial rise followed by a return toward normal in fasting and diets 1 and 3 and was normal after 7 days of refeeding (Table II). These changes in serum uric acid and renal urate handling, and the decrease in renal creatinine clearance in fasting, and the three diets are reported elsewhere $(17,18)$. No episode of gout occurred. Diet 3 and fasting caused a progressive decrease in plasma urea nitrogen, but no change occurred with diet 1 , and an increase was observed with diet 2 (Table II). 
TABLE I

Patient Data

\begin{tabular}{|c|c|c|c|c|c|c|c|c|}
\hline \multirow[b]{2}{*}{ Patient } & \multirow[b]{2}{*}{ Age } & \multirow[b]{2}{*}{ Sex } & \multirow[b]{2}{*}{$\mathrm{Ht}$} & \multicolumn{3}{|c|}{ Weight } & \multicolumn{2}{|c|}{ Mean protein intake } \\
\hline & & & & Start & End & $\Delta$ & & Initial weight \\
\hline & $y r$ & & $\mathrm{~cm}$ & & $\mathrm{~kg}$ & & $g$ & $g / k g$ \\
\hline \multicolumn{9}{|c|}{$\begin{array}{l}\text { Constant hypocaloric } \\
\text { protein }\end{array}$} \\
\hline S. S. & 21 & $\mathbf{F}$ & 175 & 79.0 & 71.7 & -7.3 & 84.4 & 1.07 \\
\hline M. M. & 28 & $\mathbf{F}$ & 160 & 97.7 & 89.2 & -8.5 & 77.6 & 0.79 \\
\hline J. N. & 37 & $F$ & 173 & 120.4 & 111.0 & -9.4 & 84.4 & 0.70 \\
\hline A. $F$. & 24 & $\mathbf{F}$ & 157 & 86.8 & 78.6 & -8.2 & 82.0 & 0.94 \\
\hline E. C. & 32 & $\mathrm{~F}$ & 168 & 100.5 & 93.7 & -6.8 & 83.5 & 0.83 \\
\hline P. M. & 19 & $\mathbf{F}$ & 155 & 106.8 & 97.5 & -9.3 & 81.0 & 0.76 \\
\hline \multirow[t]{2}{*}{ H. R. } & 41 & $\mathbf{M}$ & 180 & 111.2 & 100.3 & -10.9 & 85.0 & 0.76 \\
\hline & & & $\overline{\mathrm{X}} \pm \mathrm{SEM}$ & $100.3 \pm 5.3$ & $91.7 \pm 5.0$ & $-8.6 \pm 0.5$ & $82.5 \pm 1.0$ & $0.84 \pm 0.05$ \\
\hline \multicolumn{9}{|c|}{$\begin{array}{l}\text { Hypocaloric protein } \\
\text { refeeding }\end{array}$} \\
\hline M. K. & 41 & $\mathbf{F}$ & 157 & 96.7 & 97.4 & +0.7 & 83.8 & 0.87 \\
\hline R. M. & 37 & $\mathbf{F}$ & 160 & 119.5 & 121.7 & +2.2 & 85.6 & 0.72 \\
\hline L. B. & 19 & $\mathbf{M}$ & 178 & 93.7 & 95.1 & +1.4 & 81.2 & 0.87 \\
\hline K. C. & 44 & $\mathbf{M}$ & 170 & 96.6 & 98.6 & +2.0 & 85.0 & 0.88 \\
\hline L. Bl. & 52 & $\mathbf{M}$ & 180 & 103.5 & 100.9 & -2.6 & 83.1 & 0.80 \\
\hline J. N. & 36 & $\mathbf{F}$ & 173 & 101.2 & 102.9 & +1.7 & 83.8 & 0.83 \\
\hline \multirow[t]{2}{*}{ J. D. } & 34 & $\mathbf{F}$ & 157 & 82.7 & 83.8 & +1.1 & 81.9 & 0.99 \\
\hline & & & $\overline{\mathrm{X}} \pm \mathrm{SEM}$ & $99.1 \pm 4.2$ & $100.0 \pm 4.3$ & $0.9 \pm 0.6$ & $83.5 \pm 0.6$ & $0.85 \pm 0.03$ \\
\hline \multicolumn{9}{|c|}{$\begin{array}{l}\text { Decreasing hypocaloric } \\
\text { protein }\end{array}$} \\
\hline J. N. & 36 & $\mathbf{F}$ & 173 & 97.0 & 88.3 & -8.7 & $82.5^{*}$ & 0.85 \\
\hline C. $\mathrm{T}$. & 46 & $\mathbf{F}$ & 155 & 89.1 & 79.8 & -9.3 & 85.0 & 0.96 \\
\hline L. B. & 19 & $\mathbf{M}$ & 178 & 89.5 & 79.5 & -10.0 & 88.1 & 0.98 \\
\hline \multirow[t]{2}{*}{ R. M. } & 36 & F & 160 & 127.3 & 115.5 & -11.8 & 82.5 & 0.65 \\
\hline & & & $\overline{\mathrm{X}} \pm \mathrm{SEM}$ & $100.7 \pm 6.8$ & $90.8 \pm 6.4$ & $-9.9 \pm 0.7$ & $84.5 \pm 1.3$ & $0.86 \pm 0.07$ \\
\hline
\end{tabular}

* Day 1 value.

No significant change occurred with any of the three dietary groups in plasma cholesterol, the differences between groups in Table II being accounted for by differing 0 time values. In contrast, a significant decline in triglycerides was observed with diets 1 and 3 and fasting, and an increase with diet 2 . A marked decrease in sodium and chloride excretion occurred with all diets and fasting, with the least chloride excretion occurring during fasting. A similar decrease in urinary potassium excretion occurred in the four groups (Table II).

The time-courses of metabolic responses to the three diets are shown in Figs. 1-4 and values are summarized for the steady state of each in Table II. The constant hypocaloric diet (diet 1 ) and the decreasing protein diet (diet 3) produced changes in circulating hormones and substrates which were similar in the following ways. Plasma glucose declined to a minimum by day 5 , remaining at or slightly above this value thereafter
(Fig. 1, Table II). Plasma insulin showed the same pattern of change, falling to $40 \%$ of postabsorptive values. Plasma IRG increased transiently in all subjects, with mean maximal increments of $35 \pm 8 \mathrm{pg} / \mathrm{ml}$ for diet 1 and $44 \pm 5 \mathrm{pg} / \mathrm{ml}$ for diet 3 occurring on days 2-7 $(P<0.05)$. However, the interindividual variation in absolute values and time-course of rise resulted in mean absolute values for both groups showing no significant change, and no diet-related differences. Associated with the decrease in glucose and insulin was a fall in blood pyruvate, without change in lactate, resulting in a rise in the lactate/pyruvate ratio, maximal at day 5 in diet 1 and day 7 in diet 3, (data for day 21 are shown in Table II). The glucogenic amino acid alanine showed an early, marked fall which was sustained in both diets (Fig. 2A). Significant decreases in threonine, proline, ornithine, and arginine $(P$ $<0.05$ ) occurred in diet 1 by day 14 , and in glutamic acid and ornithine in diet 3 by day 14 (data not shown). 
TABLE II

Steady-State Values with Hypocaloric Protein Diets and Prolonged Fast

\begin{tabular}{|c|c|c|c|c|c|}
\hline & \multicolumn{2}{|c|}{ Hypocaloric protein } & \multirow[b]{2}{*}{ Prolonged fast } & \multirow{2}{*}{$\begin{array}{l}\text { Hypocaloric } \\
\text { protein } \\
\text { refeeding }\end{array}$} & \multirow[b]{2}{*}{ Postabsorptive* } \\
\hline & Constant & Decreasing & & & \\
\hline Day of regimen & 14 & 14 & $21-28$ & 7 & 0 \\
\hline$n$ & 7 & 4 & 7 & 7 & 7 \\
\hline \multicolumn{6}{|l|}{ Substrates } \\
\hline Plasma glucose, $m g / d l$ & $86 \pm 2$ & $77 \pm 2$ & $77 \pm 4$ & $87 \pm 6$ & $94 \pm 3$ \\
\hline Blood lactate, $\mu M$ & $700 \pm 56$ & $650 \pm 66$ & $890 \pm 120$ & $900 \pm 77$ & $760 \pm 160$ \\
\hline Blood pyruvate, $\mu M$ & $56 \pm 14$ & $49 \pm 6$ & $54 \pm 12$ & $71 \pm 11$ & $75 \pm 15$ \\
\hline Plasma FFA, $\mu M$ & $750 \pm 130$ & $840 \pm 210$ & $1,260 \pm 120$ & $870 \pm 110$ & $500 \pm 80$ \\
\hline Blood glycerol, $\mu M$ & $213 \pm 35$ & $211 \pm 33$ & $232 \pm 38$ & $228 \pm 30$ & $133 \pm 21$ \\
\hline Blood $\beta$-hydroxybutyrate, $m M$ & $2.6 \pm 0.17$ & $3.5 \pm 0.49$ & $4.9 \pm 0.28$ & $2.9 \pm 0.50$ & $0.11 \pm 0.04$ \\
\hline Blood acetoacetate, $\mu M$ & $520 \pm 68$ & $650 \pm 98$ & $910 \pm 67$ & $650 \pm 84$ & $19 \pm 15$ \\
\hline Urine $\beta$-hydroxybutyrate, $\mathrm{mmol} / \mathrm{day}$ & $36 \pm 10$ & $64 \pm 11$ & $118 \pm 20$ & $40 \pm 15$ & 0 \\
\hline $\mathrm{L} / \mathrm{P}$ & $14.2 \pm 2.3$ & $13.2 \pm 0.5$ & $18.3 \pm 1.4$ & $13.8 \pm 1.6$ & $10.5 \pm 1.1$ \\
\hline$\beta \mathrm{HB} / \mathrm{AcAc}$ & $5.0 \pm 0.4$ & $5.5 \pm 0.5$ & $5.4 \pm 0.5$ & $5.8 \pm 0.6$ & $6.0 \pm 0.7$ \\
\hline \multicolumn{6}{|l|}{ Hormones } \\
\hline IRI, $n g / m l$ & $0.51 \pm 0.11$ & $0.52 \pm 0.17$ & $0.58 \pm 0.09$ & $0.58 \pm 0.11$ & $1.2 \pm 0.2$ \\
\hline IRG, $p g / m l$ & $101 \pm 17$ & $139 \pm 26$ & $78 \pm 8$ & $85 \pm 20$ & $89 \pm 19$ \\
\hline \multicolumn{6}{|l|}{ Other } \\
\hline Plasma urea nitrogen, $m g / d l$ & $12 \pm 2$ & $9 \pm 1$ & $9 \pm 2$ & $13 \pm 2$ & $13 \pm 1$ \\
\hline Plasma triglycerides, $m g / d l$ & $116 \pm 6$ & $117 \pm 20$ & $102 \pm 8$ & $126 \pm 8$ & $130 \pm 12$ \\
\hline Plasma cholesterol, $m g / d l$ & $197 \pm 13$ & $148 \pm 14$ & $167 \pm 15$ & $165 \pm 9$ & $195 \pm 10$ \\
\hline Serum creatinine, $m g / d l$ & $1.1 \pm 0.1$ & $1.0 \pm 0.06$ & $1.4 \pm 0.2$ & $1.0 \pm 0.1$ & $0.9 \pm 0.7$ \\
\hline Serum uric acid, $m g / d l$ & $10.7 \pm 0.4$ & $9.6 \pm 2.5$ & $8.1 \pm 2.2$ & $5.2 \pm 1.3$ & $6.7 \pm 1.0$ \\
\hline Blood pH (venous) & $7.34 \pm 0.01$ & $7.31 \pm 0.03$ & $7.32 \pm 0.02$ & $7.38 \pm 0.02$ & $7.36 \pm 0.01$ \\
\hline $\mathrm{PCO}_{2}, \mathrm{~mm} \mathrm{Hg}$ & $43 \pm 3$ & $40 \pm 1$ & $40 \pm 3$ & $45 \pm 4$ & $47 \pm 1$ \\
\hline $\mathrm{TCO}_{2}$, meq/liter & $24.5 \pm 1.4$ & $21.5 \pm 1.9$ & $22.9 \pm 1.9$ & $28.1 \pm 2.0$ & $27.5 \pm 1.2$ \\
\hline Urine sodium, meq/day & $24 \pm 4$ & $19 \pm 8$ & $23 \pm 11$ & $15 \pm 8$ & $80 \pm 20$ \\
\hline Potassium, meq/day $\$$ & $39 \pm 6$ & $60 \pm 18$ & $48 \pm 16$ & $50 \pm 8$ & $81 \pm 21$ \\
\hline Chloride, meq/day $\ddagger$ & $34 \pm 7$ & $41 \pm 12$ & $15 \pm 4$ & $32 \pm 16$ & $89 \pm 19$ \\
\hline
\end{tabular}

* Values from day 0 of the constant hypocaloric protein group.

$\$$ All subjects received 16 meq of potassium as $\mathrm{KCl}$ daily.
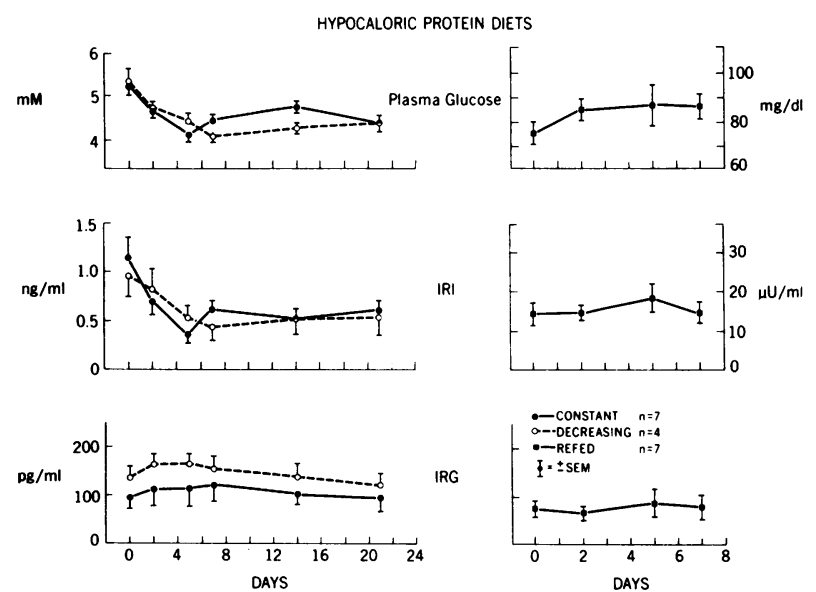

FIgURE 1 Plasma glucose, IRI and IRG in the hypocaloric protein diets. Results are shown for the constant diet (diet 1, $0, n=7$ ), refeeding after 20-28 day total fasting (diet $2, \mathbf{a}$, $n=7$ ) and for the diet with stepwise decrements of protein for 14 day (diet $3, \bigcirc, n=14$ ). Data are plotted as mean $\pm S E M$. Statistical analyses are described in the text.
Notable are the failure of glutamine to change significantly and the absence of differences in glutamine between these diets and the fall in glycine in diet 1 (Fig. 2A). Transient increases in the branched-chain amino acids, valine, leucine, and isoleucine, on days 2, 5, and 7 were followed by a return to postabsorptive levels (Fig. 2B).

A progressive rise to plateau plasma FFA values by day 7 occurred with diets 1 and 3 , but the rise in blood glycerol was more rapid with diet 3 (Table II, Fig. 3). Further divergences between the two responses are found in blood and urine ketone bodies (Fig. 4). Blood 3-hydroxybutyrate in diet 1 plateaued between 2.3 and $3.0 \mathrm{mM}$ during days 7-21. With diet 3 , 3-hydroxybutyrate rose progressively throughout the 21 days, resulting in significantly higher levels on days 14 and 21 ( $P<0.05$ ). (Peak value was $4.3 \mathrm{mM}$ on day 21.) Acetoacetate levels were not different, resulting in a higher 3-hydroxybutyrate/acetoacetate ratio in diet 3 on those days. Corresponding to the higher blood 3-hydroxybutyrate were greater urinary excre- 

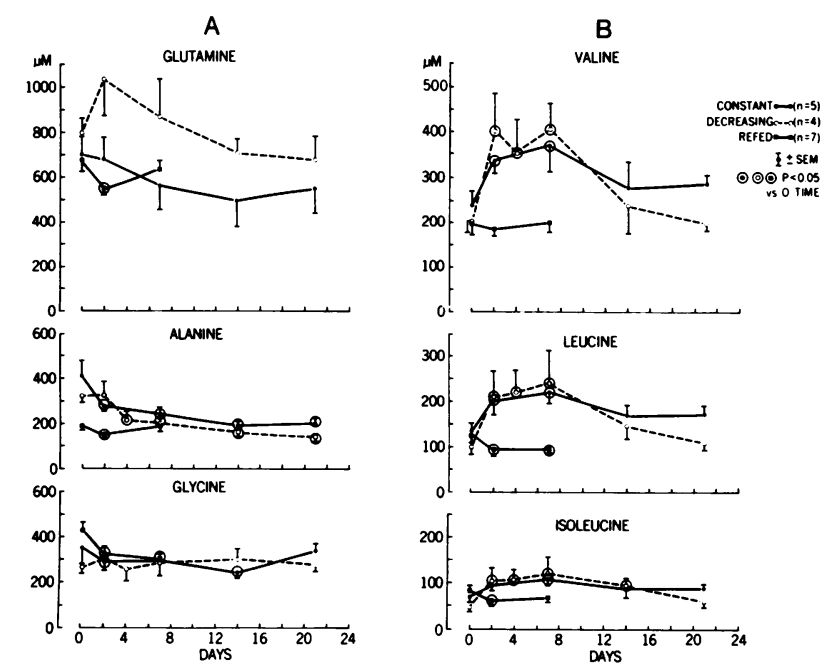

FIGURE 2 Blood levels of selected individual glucogenic amino acids (A) and the branched-chain amino acids (B) during the three hypocaloric protein diet protocols. Data are plotted with 0 days representing commencement of each diet, using the same symbols as in Fig. 1. Circled values signify a significant change from day 0 of that diet $(P<0.05$, paired $t$ test).

tions in diet 3 between days 7 and 21 . Another difference between the two diets was in blood glycine, which remained constant in diet 3.

These hormones and substrates were associated with very different patterns of nitrogen balance, for which the time-course is seen in Fig. 5, and details for day 14 and cumulative values are presented in Table II. With diet 1 , urine urea-nitrogen excretion approximated nitrogen intake for the 1st wk, then declined to 2-4 $\mathrm{g} /$ day less than the intake. With development of the ketoacidosis, ammonium nitrogen excretion increased, and uric acid excretion decreased. The sum of these urine nitrogen components exceeded the intake for the 1st wk, and was near that value thereafter. Hence, with estimates of unmeasured urine nitrogen components, fecal and integumentary losses included, a small net negative nitrogen balance existed for the first 12 days, but balance was not significantly different from zero thereafter. Thus, the cumulative negative nitrogen balance was $20 \mathrm{~g} / 21$ days. In contrast, in diet 3 the net nitrogen balance remained constantly negative at 4-6 g/day with a decrease in excretion of urea nitrogen balancing the decrease in protein intake. Ammonium nitrogen increased, again concurrent with the development of acidosis. The cumulative negative nitrogen balance was greater than that of diet 1, namely $117 \mathrm{~g} / 21$ days, but less than that for total fasting.

Urine 3-methylhistidine excretion (Fig. 6), a reflection of muscle protein catabolism, decreased during total fasting to values $67 \%$ those of day 1 . Values with diet 1 , began at $180 \mu \mathrm{mol} /$ day more than with fasting,
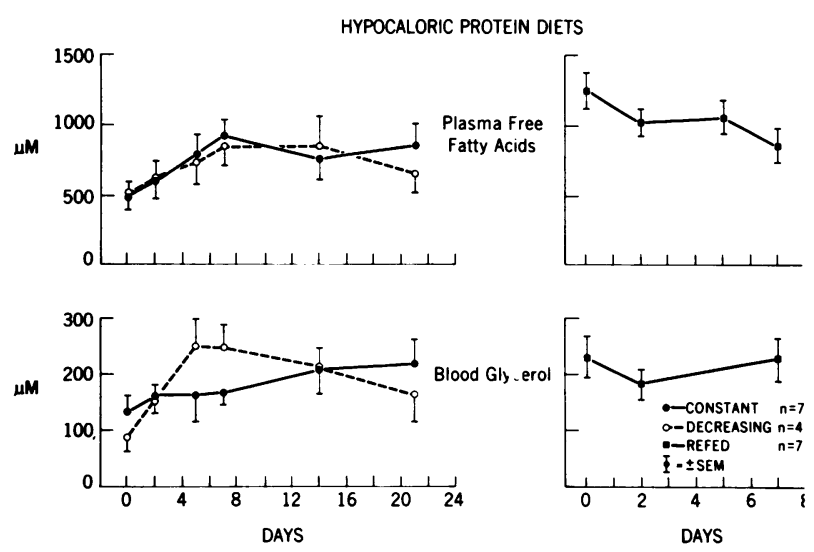

FIGURE 3 Plasma free fatty acids and blood glycerol in the three hypocaloric protein diet protocols. Data are shown as in Fig. 1.

reflecting the excretion due to the ingested protein. Through intake was constant, a significant decline occurred between days 7-14, and a further decrease to $50 \%$ day 1 values was observed by day 21 . This excretion of $177 \pm 24 \mu \mathrm{mol} /$ day was the same as during day 1 of fasting, but $>$ day 21 of fasting $(P<0.05)$. With $\operatorname{diet} 3$, excretion also decreased between days 7 and 14 , remaining significantly less than with diet 1 , but greater than with fasting, except on day 21.

The refeeding with the constant protein intake in diet 2 is presented separately because the 0 time base line was that of prolonged fasting. It caused a return of hormone and substrate values from those characteristic of prolonged fasting to those reported for the

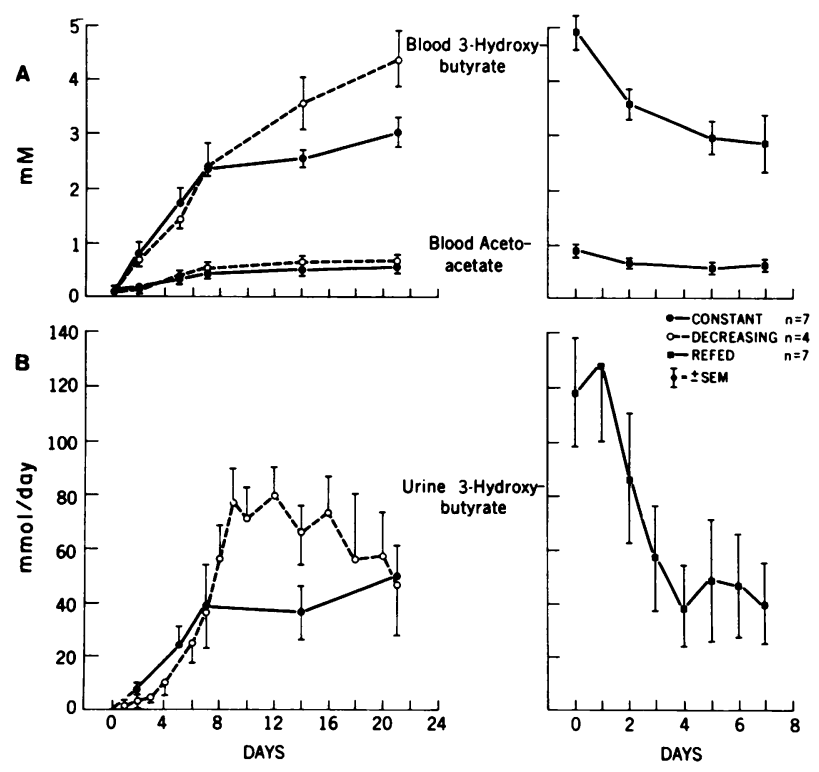

FIGURE 4 Blood 3-hydroxybutyrate and acetoacetate (A) and 24-h urinary 3-hydroxybutyrate excretion $(B)$ in the three hypocaloric protein diet protocols. Data are shown as in Fig. 1. 

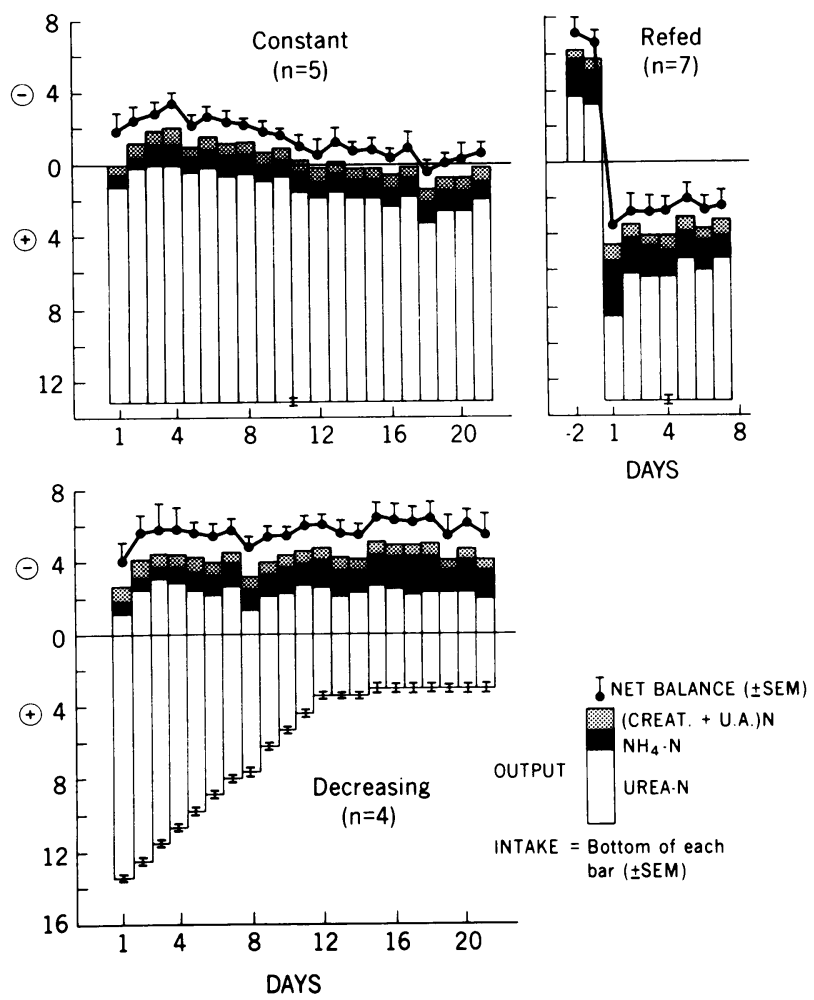

FIGURE 5 Nitrogen balance in the three hypocaloric protein diet protocols. Nitrogen intake is plotted downward from the horizontal axis, and mean $\pm S E M$ of intake is indicated at the bases of the bars. Output components are plotted upward from the intake levels, and the net balance is indicated by the closed circles and solid line for each day. The method of calculation of balance is detailed in the text. For the refeeding diet, two days $(-2$ and -1$)$ of the prior total fasting balance are shown for contrast with the response to the exogenous protein.

steady state with diet 1 . Plasma glucose rose significantly by $10 \mathrm{mg} /$ day 1 , despite the lack of measurable changes in either IRI or IRG (Fig. 1). Blood lactate remained stable, but pyruvate rose from the low values of fasting, such that the lactate/pyruvate ratio decreased significantly (Table II). The whole-blood amino acid pattern showed several changes: a transient, significant decline $(P<0.05)$ on day 2 occurred for alanine, glutamine, (Fig. 2A), threonine, serine, and asparagine, (not shown), as well as a smaller decline for the branched-chain amino acids (Fig. 2B), phenylalanine and tyrosine (not shown). Most returned to day 0 values by day 7 . The elevated glycine values typical of prolonged fasting showed a progressive decrease to normal postabsorptive levels (Fig. 2A). Plasma FFA decreased by one-third from $1,257 \pm 121 \mu \mathrm{M}$, from day 2 on, (Fig. 3), and though blood and urine ketone bodies declined more slowly (Fig. 4), all returned by day 5 to the same levels as during days 14-21 of the constant diet. Blood glycerol did not change. The steady-state negative balance of nitrogen with fasting, of $\cong 6 \mathrm{~g} /$ day, was converted to significant positive balance (Table III, Fig. 5). A marked disparity between the nitrogen intake and that appearing as urinary urea nitrogen persisted through the whole period, including days 5-7 when the plasma urea-nitrogen concentration had returned to normal (Table II). The urine ammonium nitrogen decreased concurrently with decreasing acidosis. The cumulative positive nitrogen balance for this 7-day period was $20 \mathrm{~g}$. (Inclusion of a calculation for the change in urea pool size would only decrease this value by $\cong 0.8$ g.) 3 -Methylhistidine excretion (Fig. 6) increased from a low value typical of prolonged fasting by $152 \mu \mathrm{mol} /$ day on day 7 . This excretion was equivalent to that observed on day 14 of diet 1 .

\section{DISCUSSION}

Studies as early as the turn of the century showed that protein equilibrium cannot be attained without exogenous protein (reviewed in 38). In this early work, calories were provided concurrently as carbohydrate, fat, or both. Three decades later, Strang et al. (40) showed that protein alone could produce proteinsparing. This has been elaborated upon more recently by Apfelbaum et al. (40), Flatt and Blackburn (5), Blackburn et al. (11), and Bistrian et al. $(12,14,41)$, and Bell et al. (42) who found that constant oral intake of protein alone is capable of producing protein-sparing and in some cases, protein balance. Amounts of protein employed have varied, but it would appear that about $1 \mathrm{~g} / \mathrm{kg}$ per day of high-quality protein is generally successful in achieving balance. In parenteral nutrition employing amino acid solutions alone, nitrogen balance is achieved with $\cong 1.6 \mathrm{~g} / \mathrm{kg}$ per day for one commonly used formulation (reviewed in 43). Most studies of hypocaloric amounts of protein given orally have not presented comprehensive hormone-substrate and nitrogen-balance data in homogeneous populations and with numbers of subjects amenable to statistical analysis. Accordingly, specific roles of each variable in mediating the response have not been conclusively proven.

The three protein diet protocols of the present study all produced protein-sparing. Diet 2 caused positive nitrogen balance, and the constant input (diet 1) achieved equilibrium after 12 days. The decreasing input (diet 3 ) achieved constant negative balance at a value near that of the steady state during total fasting, and therefore achieved protein-sparing only during the first $2 \mathrm{wk}$, by reference to total fasting. It is probable that the major factors in the protein-sparing were the supply of amino acids from the ingested protein, combined with decrease in protein catabolism, as inferred from the 3-methylhistidine data. 


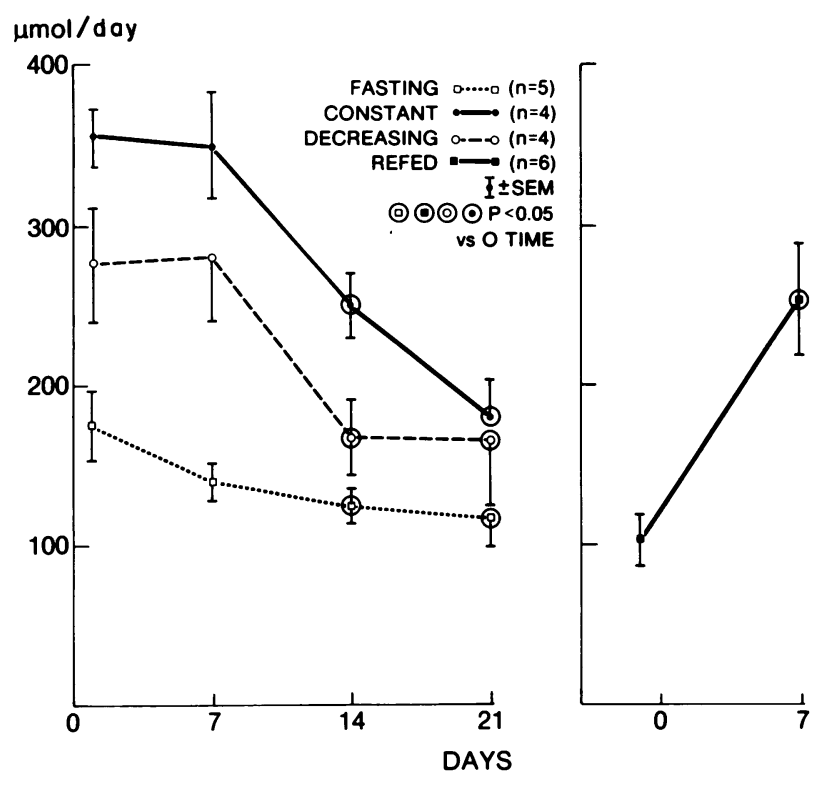

FIGURE 6 Daily urinary 3-methylhistidine excretion in the three hypocaloric protein diet protocols and total fasting. Data are shown as in Fig. 1.

In such hypocaloric states, the amount of protein required for balance is the sum of that required for maintenance of protein synthesis plus the obligate minimum which is directed into gluconeogenesis and ammoniagenesis. Using the technique of 3-methylhistidine excretion, Young et al. (44) demonstrated that muscle-protein catabolism decreases during prolonged fasting. This amino acid is found in the actin of all muscle and the myosin of white muscle. It is not catabolized or reutilized when released from peptide linkage upon proteolysis, and appears quantitatively in the urine. $75 \%$ of administered ${ }^{14} \mathrm{C}$-labeled 3-methylhistidine appears in the urine within $24 \mathrm{~h}$, and $95 \%$ within $48 \mathrm{~h}$ (45), indicating rapid and virtually quantitative excretion. The present data (Fig. 6) confirm the decrease in 3-methylhistidine excretion, and hence protein catabolism, during fasting. The magnitude of the decreases in protein catabolism and nitrogen excretion are also consistent with increased reutilization of amino acids from the catabolized muscle protein (44). The data from diet 1 , day 1 , indicate that the exogenous protein contributed 3-methylhistidine in an amount equal to that from endogenous sources, namely 170 $\mu \mathrm{mol} / \mathrm{day}^{3}{ }^{3}$ Because the input was constant, the

\footnotetext{
${ }^{3}$ With isocaloric provision of fat or carbohydrate without protein, the excretion on day 1 is the same as that of total fasting. At three different levels of protein input on day 1 , a linear relationship between protein input and 3-methylhistidine excretion has been found. The value at 0 -protein input is $170-200 \mu \mathrm{mol} / \mathrm{day}$, with an increment of $1.4 \mu \mathrm{mol} / \mathrm{day}$ per gram of protein ingested. E. B. Marliss, unpublished results.
}

dramatic decrease in excretion, from $354 \pm 18 \mu \mathrm{mol} /$ day to $177 \pm 24 \mu \mathrm{mol}$ on day 21 , must signify decreased endogenous protein catabolism, unless absorption and(or) excretion of the exogenous amino acid were selectively reduced. This suggests an even greater decrease in catabolism with this diet than with fasting alone. Quantitative interpretations with diet 3 are rendered more difficult because of the reductions in input and (probably) of endogenous catabolism during the first 14 days. On day 21 , (despite input of onequarter the amount of protein as in diet 1) excretion was not significantly different from either fasting or diet 1 , because of a large standard error of the mean (Fig. 6). This suggests that the catabolic rate was at least as great as in fasting, and certainly greater than with diet 1 . Interestingly, in diet 2, a mean increment of $152 \mu \mathrm{mol} /$ day on day 7 brought the value for excretion $(254 \pm 33 \mu \mathrm{mol} / \mathrm{day})$ to greater than on day 21 of diet $1(P<0.05)$. This would be consistent with persistence of a higher level of endogenous protein catabolism. Because it occurred during positive nitrogen balance (Fig. 5), this further implies a considerable increase in reutilization as compared with diet 1 .

Considering the concurrent 3-methylhistidine and nitrogen-balance data, certain inferences as to protein-sparing mechanisms may be drawn. Curtailed body-protein mobilization in prolonged fasting occurs via a decrease in catabolism and modest increase in reutilization (44). Protein balance with constant input of protein resulted from a considerably greater decrease in catabolism, though a modest increase in reutilization is also possible. Refeeding with the constant protein input after fasting caused positive balance in a setting with greater catabolism than in diet 1 , and therefore implies greatly increased reutilization. The data available do not give a direct measure of the protein synthetic rates, which almost certainly were reduced in fasting (46). In diet 1 , synthetic rate was equal to catabolic rate when protein balance occurred, and therefore was considerably reduced. In diet 2 , presumably synthetic rate increased, because the catabolic rate was likely to be between those of day 21 of fasting and of diet 1.

The nitrogen balances demonstrate trends which are consistent with the presence of a functional "labile nitrogen pool" (38). The size of this pool is estimated in total fasting by the difference between actual loss which decreases progressively over the first 2 wk (35), and the obligate minimum loss, represented by the plateau seen thereafter. For the first 2 wk of fasting, the cumulative value of these differences (using $6 \mathrm{~g}$ / day as obligate minimum) is $28 \mathrm{~g} \mathrm{~N}$ (data not shown). In diet 1 , the cumulative net negative balance for the same duration was $27 \mathrm{~g} \mathrm{~N}$, a strikingly similar value. In diet 3 , the pattern of input provided appeared to have also caused mobilization of this putative pool, 
TABLE III

Nitrogen Balance: Steady-State Values and Cumulative Balance

\begin{tabular}{|c|c|c|c|c|c|}
\hline & \multicolumn{2}{|c|}{ Hypocaloric protein } & \multirow[b]{2}{*}{ Prolonged fast } & \multirow{2}{*}{$\begin{array}{c}\text { Hypocaloric } \\
\text { protein refeeding }\end{array}$} & \multirow[b]{2}{*}{ Postabsorptive* } \\
\hline & Constant & Decreasing & & & \\
\hline Day of regimen & 14 & 14 & $21-28$ & 7 & 0 \\
\hline$n$ & 5 & 4 & 7 & 7 & 7 \\
\hline Intake & $13.4 \pm 0.1$ & $3.5 \pm 0.2$ & 0 & $13.4 \pm 0.1$ & - \\
\hline \multicolumn{6}{|l|}{ Output } \\
\hline \multicolumn{6}{|l|}{ Urine } \\
\hline Urea & $11.7 \pm 1.2$ & $5.7 \pm 0.5$ & $2.5 \pm 0.8$ & $7.7 \pm 0.9$ & $12.0 \pm 1.1$ \\
\hline Ammonium & $0.91 \pm 0.18$ & $1.50 \pm 0.20$ & $1.74 \pm 0.36$ & $1.28 \pm 0.18$ & $0.50 \pm 0.06$ \\
\hline Uric acid & $0.16 \pm 0.02$ & $0.19 \pm 0.03$ & $0.11 \pm 0.01$ & $0.22 \pm 0.04$ & $0.30 \pm 0.01$ \\
\hline Creatinine & $0.57 \pm 0.06$ & $0.50 \pm 0.07$ & $0.43 \pm 0.06$ & $0.59 \pm 0.08$ & $0.57 \pm 0.08$ \\
\hline Unmeasured (est.) & 0.5 & 0.5 & 0.5 & 0.5 & 0.5 \\
\hline Feces (est. from [17]) & 0.4 & 0.4 & - & 0.4 & 1.0 \\
\hline Integument (est. from [37]) & $0.46 \pm 0.02$ & $0.45 \pm 0.04$ & $0.50 \pm 0.02$ & $0.50 \pm 0.02$ & $0.50 \pm 0.03$ \\
\hline Total & $14.2 \pm 0.4$ & $9.1 \pm 0.5$ & $5.7 \pm 0.8$ & $11.1 \pm 0.9$ & $14.5 \pm 0.7$ \\
\hline $\begin{array}{l}\text { Net balance } \\
\text { Cumulative balance }\end{array}$ & $-0.80 \pm 0.37$ & $-5.3 \pm 0.7$ & $-5.7 \pm 0.8$ & $+2.3 \pm 0.9$ & - \\
\hline g N & $-29.4 \pm 5.4$ & $-117.0 \pm 14.8$ & $-167.5 \pm 8.1$ & $+19.8 \pm 5.1$ & - \\
\hline Duration (days) & 21 & 21 & 21 & 7 & - \\
\hline
\end{tabular}

* Values from day 0 of the constant hypocaloric protein group.

because the constant negative balance which occurred from the outset was identical to the obligate minimum of prolonged fasting.

Further evidence suggests that mechanisms of the protein-sparing observed are analogous to those resulting in the progressive curtailment of protein loss with total fasting. The circulating amino acid levels in diets 1 and 3 show patterns like those reported for prolonged fasting, with respect to most glucogenic amino acids as well as the branched-chain amino acids (47). The fall in alanine levels in fasting is due to a decrease in muscle release despite sustained increase in fractional extraction by the liver $(47,48)$. The transient rise in branched-chain amino acids in fasting is considered to be due to early increase in protein catabolism and thereupon release from muscle, mediated by the fall in insulin. The later decline is related to the decrease in net protein catabolism despite persistence of low insulin levels. The same trends in branched-chain amino acids in the present study suggest that similar mechanisms apply as well in diets 1 and 3 . In diets 2 , it is noteworthy that a further fall in alanine and branched-chain amino acid levels occurred. Because 3-methylhistidine excretion increased, this fall would be more consistent with increased anabolism than decreased catabolism. The recent demonstration that branched-chain amino acids are able to stimulate muscle protein synthesis directly in an isolated system (49) would further support the notion that these diets could directly influence protein synthesis via substrate supply. Branched-chain amino acids constitute $>20 \%$ of the amino acids in the protein given. In fasting (47), as in most states of protein deficiency (50), glycine levels rise. The notion of glycine levels as an indicator of the presence of exogenous protein supply is supported by the failure of levels to rise in the constant and decreasing protein diets, and the fall with refeeding.

Turning to other factors potentially responsible for mediating the responses observed, one which can be excluded as quantitatively significant, is the caloric value of the protein itself. Though the administration of nonprotein calories as glucose is protein-sparing in prolonged fasting, as in the postabsorptive state (3), protein equilibrium has never been achieved whether the input was hypocaloric (51) or isocaloric (52).

The roles of hormones in this response remain controversial. The earlier hypothesis that low insulin combined with high or postabsorptive glucagon levels constitute a "catabolic" milieu, and that high insulin and lowered glucagon levels are "anabolic" is applicable only in some circumstances (reviewed in reference 4). The more recent notion that low insulin levels in hypocaloric states are both necessary and sufficient to obtain protein-sparing with hypocaloric amounts of protein has also been challenged (vide supra). The present data again show that below postabsorptive insulin levels are a "sufficient" condition in which protein-sparing may be obtained $(5-8,14-16,41,43) .{ }^{1}$ It is not certain that this is a "necessary" condition for the organism to supply its caloric deficit from stored fat $(4,8,43),{ }^{1}$ however. It is clear that insulin levels are 
not the absolute determinants of protein-sparing, because they were indistinguishable in the steady states of all three diets and prolonged fasting. The insulin levels reported represent those prevailing in the overnight-fasted state. Subjects of diets 1 and 2 showed no significant change in peripheral IRI in relation to meals when monitored during days 21 and 7 , respectively; ${ }^{4}$ hence the values reported are likely to be representative for the whole day.

The rates of fat mobilization and utilization with these diets are the determinants of how much protein may be "saved" from catabolism for energy production. In diet 1 , it may be inferred that the caloric deficit was made up to a greater extent by endogenous fat after $2 \mathrm{wk}$, in light of the pattern of nitrogen balance. Commencement of nitrogen balance coincided with the time required to attain maximum levels and excretion of ketone bodies. A similar inference may be drawn in diet 3: though protein intake decreased, the negative balance remained constant while ketone body levels rose progressively and to higher levels than in diet 1. Despite this greater ketosis, more negative nitrogen balance was obtained with diet 3 than 1 . However, fat mobilization and ketogenesis are not necessarily related to ketonemia and ketonuria, because of changing patterns of fatty acid and ketone body utilization as well as excretion with time (53). The positive nitrogen balance of diet 2 could have resulted from administration of protein during established maximal fat mobilization. However, positive $\mathrm{N}$ balance persisted at lower levels of fat-derived substrates. Therefore, the antecedent protein depletion $(-168 \mathrm{~g} \mathrm{~N}$ at 0 time of refeeding), probably played a role in the greater nitrogen retention. This effect of prior depletion in increasing the retention of protein has long been recognized, in the absence of ketosis (38). Its mechanism is unclear but would be consistent with the existence within the organism of a means of recognition of its protein balance status, independent of insulin levels. However, the recent demonstration of altered insulin receptor number and(or) affinity in prolonged fasted and refed man (54) raises the possibility that altered "effectiveness" of insulin may be a determinant.

If increases in protein synthesis contribute to the different levels of protein-sparing observed with the three diets, it would be predicted that the energy cost of such synthesis would be provided primarily from fatty acids. Thus the lower levels of FFA and ketones in these diets than in total fasting could reflect increased utilization for this purpose, at comparable rates of production. For example, in diet 2 , a change in nitrogen balance from -6 to $+3 \mathrm{~g} /$ day, might represent an increase in synthesis of $56 \mathrm{~g}$ protein. At an estimated energy requirement of $4 \mathrm{Kcal} / \mathrm{g}$ protein synthesized, this would

\footnotetext{
${ }^{4}$ Marliss, E. B. Unpublished data.
}

require $200 \mathrm{Kcal} /$ day more than during total fasting. Detailed studies of not only protein turnover, but of fatty acid turnover, oxygen consumption, and carbon dioxide production will be required to quantify this factor.

From the therapeutic standpoint, apart from the suppression of appetite related to the state of controlled, mild ketoacidosis, the approach of employing such drastically hypocaloric ketogenic diets as therapy for obesity has no unique advantages in terms of protein conservation, except when compared with total fasting (55). The short-term efficacy of these diets for weight loss, and their safety when used in healthy individuals and under closely supervised hospital surroundings have been confirmed. However, only $25 \%$ of the patients so treated either maintained the loss or continued to lose weight in subsequent follow-up. ${ }^{5}$ The adverse symptomatology observed was part of the physiological response, namely lightheadedness due to postural hypotension, and constipation. The utility of this type of diet as a phase in refeeding after total fasting has been demonstrated, in that minimal water retention occurred. It is stressed that the addition of exogenous energy as small amounts of carbohydrate appears not to mitigate the benefit of the amounts of protein administered $(8,10,13)$ in respect to protein-sparing, and may be advantageous in that less adverse symptomatology accompanies the lesser ketosis.

\section{ACKNOWLEDGMENTS}

The authors express their sincere gratitude to Thelma Peregrino-Solomon, Katarina Thumm, Chou-Nan Wei, and Hin-Luen Tang for their assiduous technical assistance; to Diane Marliss for her excellent secretarial assistance; and to Dr. K. N. Jeejeebhoy and Dr. G. H. Anderson for their constructive reviews of this study.

This work was supported by grants from the Medical Research Council of Canada (MA 4782), from the Bickell Foundation (Toronto) and from the Norman Urquhart Foundation (Toronto General Hospital).

\section{REFERENCES}

1. Marliss, E. B., F. T. Murray, and A. F. Nakhooda. 1976. Metabolic response to hypocaloric protein diets. Clin. Res. 24: 681A. (Abstr.)

2. Marliss, E. B. 1977. Factors in protein sparing by hypocaloric protein diets. Clin. Res. 25: 538A. (Abstr.)

3. Gamble, J. L. 1946-47. Physiological information gained from studies on the life raft ration. Harvey Lect. 42: 247-273.

4. Marliss, E. B. 1977. An overview of amino acid metabolism: the determinants of protein homeostasis in parenteral nutrition. In Symposium on Clinical Nutrition Update: Amino Acids. American Medical Association. Chicago, Ill. 34-46.

5. Flatt, J. P., and G. L. Blackburn. 1974. The metabolic fuel regulatory system: implications for protein-sparing

${ }^{5}$ Marliss, E. B. Unpublished observations. 
therapies during caloric deprivation and disease. Am. J. Clin. Nutr. 27: 175-187.

6. Blackburn, G. L., J. P. Flatt, and T. W. Hensle. 1975. Peripheral amino acid infusions. In Total Parenteral Nutrition. J. E. Fischer, editor. Little, Brown \& Co., Boston. 32-41.

7. Blackburn, G. L., J. P. Flatt, G. H. A. Clowes, T. F. O'Donnell, and T. E. Hensle. 1973. Protein-sparing therapy during periods of starvation with sepsis or trauma. Ann. Surg. 177: 588-594.

8. Greenberg, G. R., E. B. Marliss, G. H. Anderson, B. Langer, W. Spence, E. B. Tovee, and K. N. Jeejeebhoy. 1976. Protein-sparing therapy in post-operative patients. Effects of added hypocaloric glucose or lipid. N. Engl. J. Med. 294: 1411-1416.

9. Jeejeebhoy, K. N., G. H. Anderson, A. F. Nakhooda, G. R. Greenberg, I. Sanderson, and E. B. Marliss. 1976. Metabolic studies in total parenteral nutrition with lipid in man: comparison with glucose. J. Clin. Invest. 57: $125-136$.

10. Genuth, S. M., J. H. Castro, and V. Vertes. 1974. Weight reduction in obesity by outpatient semistarvation. J. Am. Med. Assoc. 230: 987-991.

11. Blackburn, G. L., B. R. Bistrian, J. P. Flatt, and J. Sizer. 1975. Role of a protein-sparing modified fast in a comprehensive weight reduction program. In Recent Advances in Obesity Research. A. Howard, editor. London, Newman Publishing Ltd. 1: 279-286.

12. Bistrian, B. R., G.L. Blackburn, and J. B. Stanbury, 1977. Metabolic aspects of a protein-sparing modified fast in the dietary management of Prader-Willi obesity. N. Engl. J. Med. 296: 774-779.

13. Baird, I. M., R. L. Parsons, and A. N. Howard. 1974. Clinical and metabolic studies of chemically defined diets in the management of obesity. Metab. Clin. Exp. 23: 645-657.

14. Bistrian, B. R., G. L. Blackburn, J. P. Flatt, J. Sizer, N. Scrimshaw, and M. Sherman. 1976. Nitrogen metabolism and insulin requirements in obese diabetic adults on a protein-sparing modified fast. Diabetes. 25: 494504.

15. Hoover, H. C., Jr., J. P. Grant, C. Gorschboth, and A. Ketcham. 1975. Nitrogen-sparing intravenous fluids in postoperative patients. $N$. Engl. J. Med. 293: 172-175.

16. Blackburn, G. L., J. P. Flatt, G. H. A. Clowes, and T. E. O'Donnell. 1973. Peripheral intravenous feeding with isotonic amino acid solutions. Am. J. Surg. 125: 447-454.

17. Fox, I. H., M. L. Halperin, M. B. Goldstein, and E. B. Marliss. 1976. Renal excretion of uric acid during prolonged fasting. Metab. Clin. Exp. 25: 551-559.

18. Stinebaugh, B. J., E. B. Marliss, F. X. Schloeder, I. H. Fox, M. B. Goldstein, and M. L. Halperin. 1975. The mechanism for the paradoxical aciduria following alkali administration to prolonged-fasted subjects. Metab. Clin. Exp. 24: 915-922.

19. Streja, D., G. Steiner, E. B. Marliss, and M. Vranic, 1977. The turnover and recycling of glucose in man during prolonged fasting. Metab. Clin. Exp. 26: 1089-1098.

20. Streja, D., E. B. Marliss, and G. Steiner. 1977. The effects of prolonged fasting on plasma triglyceride kinetics in man. Metab. Clin. Exp. 26: 505-516.

21. Adams, C. F. 1975. Nutritive Value of American Foods in Common Units. Agriculture Handbook No. 456. U. S. Department of Agriculture. Washington, D. C.

22. Autoanalyzer Method AA 11-02. Technicon Instruments Corporation. Tarrytown, N. Y.

23. Passonneau, J. V. 1974. L(+)-Lactate. Fluorimetric
Method. In Methods of Enzymatic Analysis. 2nd edition. H. U. Bergmeyer, editor. Academic Press, Inc., New York. 1468-1472.

24. Passonneau, J. V., and O. H. Lowry. 1974. Pyruvate Fluorimetric Assay. In Methods of Enzymatic Analysis. 2nd edition. H. U. Bergmeyer, editor. Academic Press, Inc., New York. 1452-1456.

25. Mellanby, J., and D. H. Williamson. 1974. D-(-)-3-Hydroxybutyrate. In Methods of Enzymatic Analysis. 2nd edition. H. U. Bergmeyer, editor. Academic Press, Inc., New York. 1836-1839.

26. Mellanby, J., and D. H. Williamson. 1974. Acetoacetate. In Methods of Enzymatic Analysis. 2nd edition. H. U. Bergmeyer, editor. Academic Press, Inc., New York. 1840-1843.

27. Wieland, O. 1974. Glycerol. In Methods of Enzymatic Analysis. 2nd edition. H. U. Bergmeyer, editor. Academic Press, Inc., New York. 1404-1409.

28. Kedenburg, C. P. 1971. A lithium buffer system for accelerated single column amino acid analysis in physiological fluids. Anal. Biochem. 40: 35-42.

29. Ho, R. J. 1970. Radiochemical assay of long-chain fatty acids using ${ }^{63} \mathrm{Ni}$ as tracer. Anal. Biochem. 36: $105-113$.

30. Herbert, V., K. S. Law, C. W. Gottleib, and S. J. Bleicher. 1965. Coated charcoal immunoassay of insulin. J. Clin. Endocrinol. Metab. 25: 1375-1384.

31. Kuku, S. F., A. Zeidler, S. Emmanouel, A. I. Katz, and A. H. Rubenstein. 1976. Heterogeneity of plasma glucagon: Patterns in patients with chronic renal failure and diabetes. J. Clin. Endocrinol. Metab. 42: 173-179.

32. Autoanalyzer Method AA11-01 Technicon Instruments Corporation, Tarrytown, N. Y.

33. Autoanalyzer Method N11a. Technicon Instruments Corporation, Tarrytown, N. Y.

34. Brown, R. N., and E. F. Freier. 1967. Improved automated carbonate procedure for serum urate. Clin. Biochem. 1: 154-171.

35. Owen, O. E., P. Felig, A. P. Morgan, J. Wahren, and G. F. Cahill, Jr. 1969. Liver and kidney metabolism during prolonged starvation. J. Clin. Invest. 48: 574-583.

36. Association of Official Agriculture Chemists. 1965. Official methods of analysis. AOAC Washington, D. C. 19th edition. 16-19.

37. Joint FAO/WHO Expert Committee: Energy and Protein requirements. 1973. WHO Technical Reports Series 522. Geneva. World Health Organization.

38. Munro, H. N. 1964. General aspects of the regulation of protein metabolism by diet and hormones. In Mammalian Protein Metabolism. H. N. Munro and J. B. Allison, editors. Academic Press, Inc., New York. 1: 382-393.

39. Strang, J. M., F. A. Evans, and H. B. McCluggage. 1930. Further studies in the dietary correction of obesity. Am. J. Med. Sci. 179: 687-694.

40. Apfelbaum, M., P. Boudon, D. Lacatis, and P. Nillus. 1970. Effets Métaboliques de la diète protidique chez 41 sujets obèses. Presse Med. 78: 1917-1920.

41. Bistrian, B. R., J. Winterer, G. L. Blackburn, V. Young, and M. Sherman. 1977. Effect of a protein-sparing diet and brief fast on nitrogen metabolism in mildly obese subjects. J. Lab. Clin. Med. 89: 1030-1035.

42. Bell, J. D., S. Margen, and D. H. Calloway. 1969. Ketosis, weight loss, uric acid and nitrogen balance in obese women fed single nutrients at low caloric levels. Metab. Clin. Exp. 18: 193-208.

43. Jeejeebhoy, K. N. 1977. Protein-sparing effect of amino acids. In Clinical Nutrition Update. Amino Acids. American Medical Association, Chicago, Ill. 65-72. 
44. Young, V. R., L. N. Haverberg, C. Bilmazes, and H. N. Munro. 1973. Potential use of 3-methylhistidine excretion as an index of progressive reduction in muscle protein catabolism during starvation. Metab. Clin. Exp. 22: 1429-1436.

45. Long, C. L., L. N. Haverberg, V. R. Young, J. M. Kinney, H. N. Munro, and J. W. Geiger. 1975. Metabolism of 3-methylhistidine in man. Metab. Clin. Exp. 24: 929935.

46. Waterlow, J. C., P. J. Garlick, and D. J. Millward. 1977. Amino acid Supply and Protein Turnover. In Clinical Nutrition Update: Amino Acids. American Medical Association, Chicago, Ill. 1-9.

47. Felig, P., O. E. Owen, J. Wahren, and G. F. Cahill, Jr. 1969. Amino acid metabolism in prolonged fasting. J. Clin. Invest. 48: 584-594.

48. Felig, P., T. Pozefsky, E. B. Marliss, and G. F. Cahill, Jr. 1970. Alanine: central role in carbohydrate and protein metabolism. Science (Wash. D. C.). 167: 1003-1004.

49. Atwell, J. R., M. P. Hedden, V. J. Mancusi, and M. G. Buse. 1977. Branched chain amino acids (BCAA) as regulators of muscle protein synthesis. Diabetes. 26(Suppl. 1): 373. (Abstr.)
50. Holt, L. E., S. E. Snyderman, P. M. Norton, and E. Roitman. 1968. The plasma aminogram as affected by protein intake. In Protein Nutrition and Free Amino Acid Patterns. J. H. Leathem, editor. Rutgers University Press. New Brunswick, N. J. 32-38.

51. Cahill, G. F., Jr., T. T. Aoki, and E. B. Marliss. 1972. Insulin and muscle protein. Handb. Physiol. 1: 563577.

52. O'Connell, R. C., A. P. Morgan, T. T. Aoki, M. R. Ball, and F. D. Moore. 1974. Nitrogen conservation in starvation. Graded responses to intravenous glucose. J. Clin. Endocrinol. Metab. 39: 555-563.

53. Owen, O. E., and G. A. Reichard. 1975. Ketone body metabolism in normal, obese, and diabetic subjects. Isr. J. Med. Sci. 11: 560-570.

54. DeFronzo, R., R. Sherwin, V. Soman, R. Hendler, and P. Felig. 1977. Dissociation of insulin binding to monocytes and insulin action in intact man during starvation and refeeding. Clin. Res. 25: 494A. (Abstr.)

55. Yang, M-U, and T. C. Van Itallie. 1976. Composition of weight lost during short-term weight reduction. J. Clin. Invest. 58: 722-730. 